Research Paper

\title{
The Impact of Afatinib on Survival in Advanced Non-Small Cell Lung Cancer: A Meta-Analysis of Randomized Controlled Trials
}

\author{
Chi Wang ${ }^{1}$, Yun $\mathrm{Li}^{1}$, Li Ke² , Lejie Cao ${ }^{3}$, Pingsheng Fan ${ }^{4}$, Zhiwei $\mathrm{Wu}^{1}$, Quan $\mathrm{Wu}^{1}{ }^{\circledR}$ \\ 1. Central Laboratory of Medical Research Centre, Anhui Provincial Hospital, Anhui Medical University, Hefei, 230001, China \\ 2. Department of Thoracic Surgery, Anhui Provincial Hospital, Anhui Medical University, Hefei, 230001, China \\ 3. Department of Respiration, Anhui Provincial Hospital, Anhui Medical University, Hefei, 230001, China \\ 4. Department of Oncology, Anhui Provincial Hospital, Anhui Medical University, Hefei, 230001, China \\ $\triangle$ Corresponding author: Dr. Quan Wu. Address for correspondence: Central Laboratory of Medical Research Centre, 17 Lujian Road, Luyang District, Hefei, \\ China. Email: powerwoo01@ahmu.edu.cn \\ (C) Ivyspring International Publisher. This is an open access article distributed under the terms of the Creative Commons Attribution (CC BY-NC) license \\ (https://creativecommons.org/licenses/by-nc/4.0/). See http://ivyspring.com/terms for full terms and conditions.
}

Received: 2018.05.28; Accepted: 2018.12.21; Published: 2019.01.29

\begin{abstract}
Background: Afatinib is a second-generation epidermal growth factor receptor-tyrosine kinase inhibitor (EGFR-TKI) that has been approved by the Food and Drug Administration for the treatment of advanced non-small cell lung cancer (NSCLC) harboring EGFR mutations. We performed a meta-analysis to assess the efficacy and safety of afatinib in advanced NSCLC.

Methods: We searched PubMed, PMC database, EMBASE, Cochrane Library and Web of Science to obtain the relevant literature. The efficacy and safety of afatinib was assessed based on progression-free survival (PFS), overall survival (OS), overall response rate (ORR), primary grade $3 / 4$ adverse events and fatal adverse events (FAEs). A subgroup analysis was performed according to control type for all end-points.

Results: Seven randomized controlled trials were included, with a total of 3093 patients. The meta-analysis showed that afatinib treatment significantly prolonged PFS in patients compared with control groups $(\mathrm{HR}=$ $0.57,95 \% \mathrm{Cl}: 0.42-0.76 ; \mathrm{P}=0.00)$, increased $\mathrm{OS}(\mathrm{HR}=0.91,95 \% \mathrm{Cl}: 0.83-0.99 ; \mathrm{P}=0.04)$ and $\mathrm{ORR}(\mathrm{RR}=1.82$, $95 \% \mathrm{Cl}: 1.13-2.93 ; \mathrm{P}=0.01)$. In terms of safety, afatinib significantly increased the incidence of diarrhea $(\mathrm{RR}=$ 8.9, 95\% Cl: 5.33-14.93; $\mathrm{P}=0.00)$, rash $(\mathrm{RR}=7.31,95 \% \mathrm{Cl}: 1.56-34.12 ; \mathrm{P}=0.01)$ and stomatitis $(\mathrm{RR}=6.45$, $95 \% \mathrm{Cl}$ : 1.27-32.78; $\mathrm{P}=0.03)$, compared with the control group. However, there was no significant difference in FAEs ( $R R=0.75,95 \% \mathrm{Cl}: 0.38-1.49 ; \mathrm{P}=0.41)$.

Conclusions: This meta-analysis confirmed that afatinib extended survival, improved response rates and did not increase the risk of treatment-related mortality in advanced NSCLC. As a novel EGFR-TKI, afitinib has significant potential for clinical application.
\end{abstract}

Key words: Immunotherapy, Survival, Non-small cell lung cancer, Response rate, Meta-analysis

\section{Introduction}

Lung cancer is the leading cause of cancer-related death for both men and women, the 5 -year relative survival is currently $18 \%$, and more than one-half of lung cancer patients are diagnosed at a late stage. The 5-year survival rate can be as low as $4 \%$ because of a lack of effective treatments [1]. A total of $85-90 \%$ of lung cancer cases are classified as non-small cell lung cancer (NSCLC) [2]. However, the treatment and prognosis for NSCLC are far from satisfactory. Approximately $60-70 \%$ of NSCLC patients who receive surgery eventually show postoperative recurrence and metastasis [3]. Platinum therapeutics combined with chemotherapy is the standard first-line treatment for patients with stage IIIB or IV NSCLC, but the treatments often have limited efficacy and have significant safety issues [4], so finding new targeted therapies is necessary.

Epidermal growth factor receptor (EGFR) is a membrane surface receptor [5] with tyrosine kinase activity that is widely found in human epidermis and 
stromal cells. In healthy cells, the EGFR tyrosine kinase is regulated by its ligand and can regulate cell growth and proliferation. However, for tumor cells, the EGFR tyrosine kinase is associated with proliferation, angiogenesis, invasion, metastasis and apoptosis in tumor lesions [6]. When the regulatory genes of this pathway are abnormally mutated or amplified, they can create abnormal activation of downstream pathways, and induce many cancers. In a previous study [7], genetic tests in patients with advanced NSCLC in Asian populations showed mutations in the EGFR gene in $30-50 \%$ of patients. In light of this, analysis of EGFR gene expression is currently conducted clinically. EGFR-tyrosine kinase inhibitors (EGFR-TKIs) are the first-line treatment for NSCLC in patients with EGFR-positive NSCLC [8]. A large randomized controlled clinical trial [9] has shown that EGFR-TKIs are significantly more effective than traditional chemotherapeutic agents in patients with EGFR mutations. Based on this clinical evidence of efficacy, the United States NCCN guidelines recommend that EGFR-TKIs can be used for sensitive EGFR gene mutations as a first-line treatment in NSCLC patients.

Afatinib is a second generation, irreversible, pan-HER tyrosine kinase inhibitor [10] and was first approved by the U.S. FDA on July 13, 2013, for first-line treatment of metastatic NSCLC with exon 19 deletions or exon 21 (L858R) substitution mutations [11]. It binds irreversibly to the ErbB family of receptors and inhibits the kinase domain of EGFR [12], the transphosphorylation of HER2 and HER4, and ErbB3, thereby permanently inhibiting receptor signaling and blocking the interaction with tumor cells [13, 14]. Afatinib inhibits cell proliferation, metastasis-related signal transduction, and promotes tumor cell apoptosis [15]. Several randomized controlled trials (RCTs) have been conducted to evaluate the benefits of afatinib in NSCLC. Here, we systematically combined data from relevant randomized phase II/III trials to provide a more precise assessment of the efficacy and safety of afatinib in NSCLC.

\section{Materials and methods}

\section{Data retrieval strategies}

The PubMed, PMC database, EMBASE, Cochrane Library and Web of Science electronic databases were searched to identify relevant RCTs of afatinib in NSCLC (published before August, 2018), and no language restriction was imposed. The keywords were "afatinib", "non-small cell lung cancer", "lung adenocarcinoma", and "randomized controlled trial". In addition, we also manually searched from the references in the selected literature. Only eligible original studies with an available full text were selected, and meeting abstracts were excluded. If necessary, the respective authors of some studies were contacted for further information. If duplication of data was encountered in several articles, only the most informative or complete studies were included.

\section{Inclusion and exclusion criteria}

The inclusion criteria: (1) studies were RCTs investigating the efficacy and/or safety of afatinib in the treatment of NSCLC; (2) the experimental arm was treated using afatinib or afatinib plus chemotherapy drugs and the control arm was treated using placebo, or targeted and/or chemotherapy drugs; (3) the studies included at least one of the following outcomes (PFS, progression free survival; OS, overall survival; ORR, overall response rate; AEs, adverse effects; FAEs, fatal adverse events); (4) the full text was available. The exclusion criteria: (1) non-primary literature (reviews, meeting records, editorials, letters, and communications); (2) there were not enough data to determine the results; and (3) repeated published data.

\section{Data extraction}

Two reviewers (Yun Li and Li Ke) independently extracted data from eligible studies and any discrepancies were resolved through discussion until a consensus was reached. The following information was extracted: name of the first author, publication year, phase of the trial, sample size, experimental and control arm treatment, primary end points, the hazard ratio (HR), along with 95\% confidence interval (CI) for the comparison of OS or PFS. If there was no direct report of HR and 95\% CI in the article, Tierney's method was used to estimate the survival curve [16], and median follow-up.

\section{Quality assessment}

Based on the Cochrane Collaboration guidelines, the risk of bias tool was used to evaluate the methodological quality of the RCTs. Random sequence generation, allocation concealment, blinding of participants and personnel, blinding of outcome assessment, incomplete outcome data, selective reporting and other biases were assessed [17].

\section{Statistical analysis}

Pooled data management and analysis were performed using STATA 12.0 statistical software. We used the fixed-effects models (Mantele-Haenszel method) when there was a lack of heterogeneity ( $\mathrm{P}$ $>0.1$ and $\mathrm{I}^{2}<50 \%$, and otherwise, we used the random-effects model (DerSimoniane-Laird method). 
The heterogeneity evaluation and the inconsistency statistic $\left(\mathrm{I}^{2}\right)$ is explained as follows: $\mathrm{I}^{2}=0 \%$ indicates no heterogeneity, $0 \%<\mathrm{I}^{2}<25 \%$ indicates the least heterogeneity, $25 \% \leq \mathrm{I}^{2} \quad<50 \%$ indicates mild heterogeneity, $50 \% \leq \mathrm{I}^{2}<75 \%$ indicates moderate heterogeneity, and $75 \% \leq \mathrm{I}^{2}$ indicates strong heterogeneity. For each study, the time-to-event variables, including OS, PFS and HR were calculated with 95\% confidence intervals (CI), and for the dichotomous variables, including ORR, the rate of adverse events and FAEs, RRs with 95\% CIs were calculated. A subgroup analysis was performed according to control type for all end-points. We defined all $\mathrm{p}$ values as two-sided, and $\mathrm{p}<0.05$ indicates statistical significance. Publication bias was evaluated using Begg's and Egger's test and presented using a funnel plot.

\section{Results}

\section{Literature review and characteristics of the included studies}

Using the described search strategy, 616 studies were initially identified. Of these, 229 articles were excluded because of data duplication. Of the remaining 387 articles, we excluded 344 articles after reading the title and the abstract. Of the remaining 43 articles, we excluded 36 articles after retrieval of the full-text. The selection procedure is summarized in Figure 1. A total of seven randomized clinical trials covering 3093 patients were finally included in this meta-analysis [18-24].

There were three articles that reported on afatinib vs. traditional chemotherapy [19-21], and one article reported on afatinib plus chemotherapy vs. chemotherapy [24]. Two articles reported on afatinib vs. a first generation EGFR-TKI [22, 23], and one reported on afatinib vs. placebo [18]. The detailed characteristics of the included studies are summarized in Table 1. The implementation of blinding was somewhat unsatisfactory, but other methodological problems (Supplementary Figure 1 and Supplementary Figure 2) were relatively few in these studies. The publication bias results are shown in a funnel plot in Supplementary Figure 3, and the symmetry is good, indicating that there is no obvious publication bias.

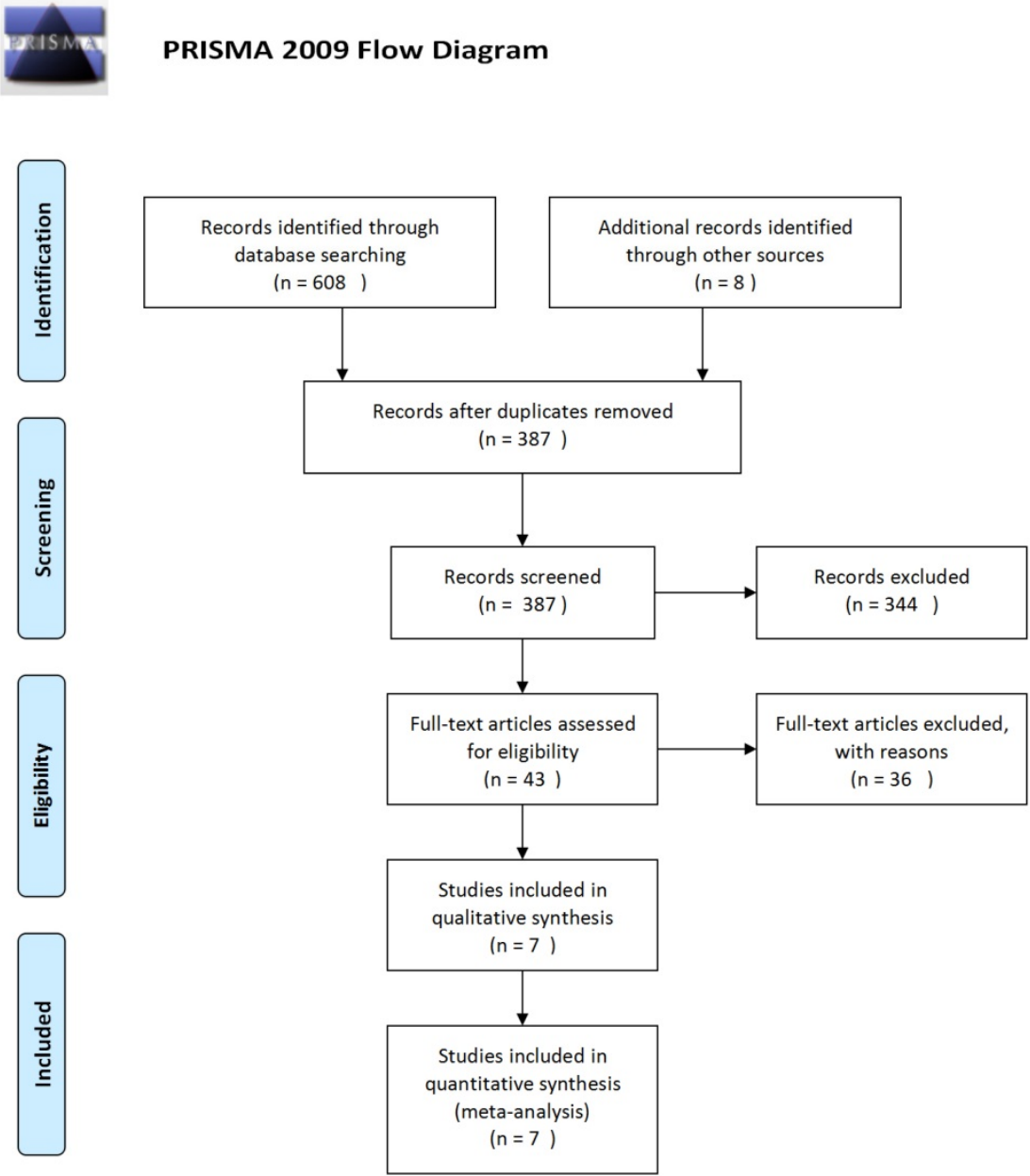

Figure 1. Flow diagram of the literature search 
Table 1. Main characteristics of the included studies

\begin{tabular}{|c|c|c|c|c|c|c|c|c|}
\hline Author & Year & Phase & Number of Patients & Treatment Regimens & Primary end-point & OS HR (95\% CI) & PFS HR (95\% CI) & follow-up (months) \\
\hline Sequist & 2013 & III & 345 & $\begin{array}{l}\text { Afatinib } \\
\text { Cisplatin plus Pemetrexed }\end{array}$ & PFS & $\begin{array}{l}0.88 \\
(0.66-1.17)\end{array}$ & $\begin{array}{l}0.58 \\
(0.43-0.78)\end{array}$ & 16.4 \\
\hline Wu & 2014 & III & 364 & $\begin{array}{l}\text { Afatinib } \\
\text { Gemcitabine and Cisplatin }\end{array}$ & PFS & $\begin{array}{l}0.93 \\
(0.72-1.22)\end{array}$ & $\begin{array}{l}0.28 \\
(0.20-0.39)\end{array}$ & $11, .0$ \\
\hline Machiels & 2015 & III & 483 & $\begin{array}{l}\text { Afatinib } \\
\text { Methotrexate }\end{array}$ & PFS & $\begin{array}{l}0.96 \\
(0.77-1.19)\end{array}$ & $\begin{array}{l}0.80 \\
(0.65-0.98)\end{array}$ & 6.7 \\
\hline Schuler & 2016 & III & 202 & $\begin{array}{l}\text { Afatinib plus chemotherapy } \\
\text { Chemotheapy }\end{array}$ & PFS & $\begin{array}{l}1.00 \\
(0.70,1.43)\end{array}$ & $\begin{array}{l}0.60 \\
(0.43-0.85)\end{array}$ & 12.2 \\
\hline Soria & 2015 & III & 795 & $\begin{array}{l}\text { Afatinib } \\
\text { Erlotinib }\end{array}$ & PFS & $\begin{array}{l}0.81 \\
(0.69-0.95)\end{array}$ & $\begin{array}{l}0.82 \\
(0.68-1.00)\end{array}$ & 18.4 \\
\hline Park & 2016 & II & 319 & $\begin{array}{l}\text { Afatinib } \\
\text { Gefitinib }\end{array}$ & PFS & $\begin{array}{l}0.87 \\
(0.66-1.15)\end{array}$ & $\begin{array}{l}0.73 \\
(0.57-0.95)\end{array}$ & 27.3 \\
\hline Miller & 2012 & II & 585 & $\begin{array}{l}\text { Afatinib } \\
\text { Placebo }\end{array}$ & PFS & $\begin{array}{l}1.08 \\
(0.86-1.36)\end{array}$ & $\begin{array}{l}0.38 \\
(0.31-0.47)\end{array}$ & 12.0 \\
\hline
\end{tabular}

OS: overall survival; HR: harzard ratio; CI: confidence interval; PFS: progression-free survival.

\begin{tabular}{|c|c|c|}
\hline Study & & $\%$ \\
\hline ID & $\mathrm{HR}(95 \% \mathrm{Cl})$ & Weight \\
\hline chemotherapy & & \\
\hline Sequist(2013) & $0.88(0.66,1.17)$ & 9.63 \\
\hline Wu(2014) & $0.93(0.72,1.22)$ & 11.35 \\
\hline Machiels(2015) & $0.96(0.77,1.19)$ & 16.66 \\
\hline Schuler(2016) & $1.00(0.70,1.43)$ & 6.19 \\
\hline Subtotal $(1-$ squared $=0.0 \%, p=0.948)$ & $0.94(0.82,1.07)$ & 43.84 \\
\hline first EGFR-TKI & & \\
\hline Soria(2015) & $0.81(0.69,0.95)$ & 30.88 \\
\hline Park(2016) & $0.87(0.66,1.15)$ & 10.24 \\
\hline Subtotal (l-squared $=0.0 \%, p=0.662$ ) & $0.82(0.72,0.95)$ & 41.12 \\
\hline placebo & & \\
\hline Miller(2012) & $1.08(0.86,1.36)$ & 15.03 \\
\hline Subtotal $(1-$ squared $=. \%, p=)$. & $1.08(0.86,1.36)$ & 15.03 \\
\hline Heterogeneity between groups: $p=0.11$ & & \\
\hline Overall (l-squared $=0.0 \%, p=0.562$ ) & $0.91(0.83,0.99)$ & 100.00 \\
\hline & & \\
\hline .2 & & \\
\hline
\end{tabular}

Figure 2. Forest plots of harzard ratios (HRs) for OS comparing afatinib-based regimens to the control arm

\section{Efficacy and safety}

In the included articles, the efficacy and safety of afatinib in the treatment of NSCLC were studied. The OS analysis covered all the included articles, and the analysis of the pooled data revealed that afatinib improved the OS in NSCLC compared with the control arm (HR $=0.91,95 \%$ CI: 0.83-0.99; $\mathrm{P}=0.04$, Figure 2). No significant heterogeneity was found in the OS analysis $\left(\mathrm{I}^{2}=0 \%\right)$, so a fixed-effects model was used. A subgroup analysis according to the control type revealed that OS was increased in the afatinib arm compared with the first-generation EGFR-TKI $\operatorname{arm}(\mathrm{HR}=0.82,95 \% \mathrm{CI}: 0.72-0.95 ; \mathrm{P}=0.01)$. However, there was no significant difference between the chemotherapy and placebo arms. In terms of PFS, considering the significant heterogeneity between studies $\left(\mathrm{I}^{2}=90 \%\right)$, a random-effects model was used.
The pooled analysis revealed that afatinib improved PFS (HR = 0.57, 95\% CI: 0.42-0.76; P = 0.00, Figure 3). The subgroup analysis revealed that afatinib-based therapy significantly improved PFS compared with all control types. The aggregate ORR was 1.82 (95\% CI: $1.13-2.93 ; \mathrm{P}=0.01 ; \mathrm{I}^{2}=89 \%$; Figure 4$)$. There was a statistically significant difference for ORR.

We selected grade III-IV diarrhea, rash and stomatitis for analysis, which were the most common toxicities among the studies. A total of 219/1862 $(11.8 \%)$ patients developed diarrhea in the experimental group and 15/1193 (1.2\%) in the control group (Supplementary Figure 4). A total of 199/1862 $(10.7 \%)$ patients developed rash in the experimental group and 46/1193 (3.9\%) in the control group (Supplementary Figure 5). A total of 90/1862 (4.8\%) patients developed stomatitis in the experimental 
group and 14/1193 (1.2\%) in the control group (Supplementary Figure 6). Moreover, among the 3093 patients in the seven included RCTs, the pooled RR was 0.75 (95\% CI: 0.38-1.49; $\mathrm{P}=0.41 ; \mathrm{I}^{2}=7.6 \%$; Figure $5)$, indicating no risk of FAEs associated with afatinib compared with controls.

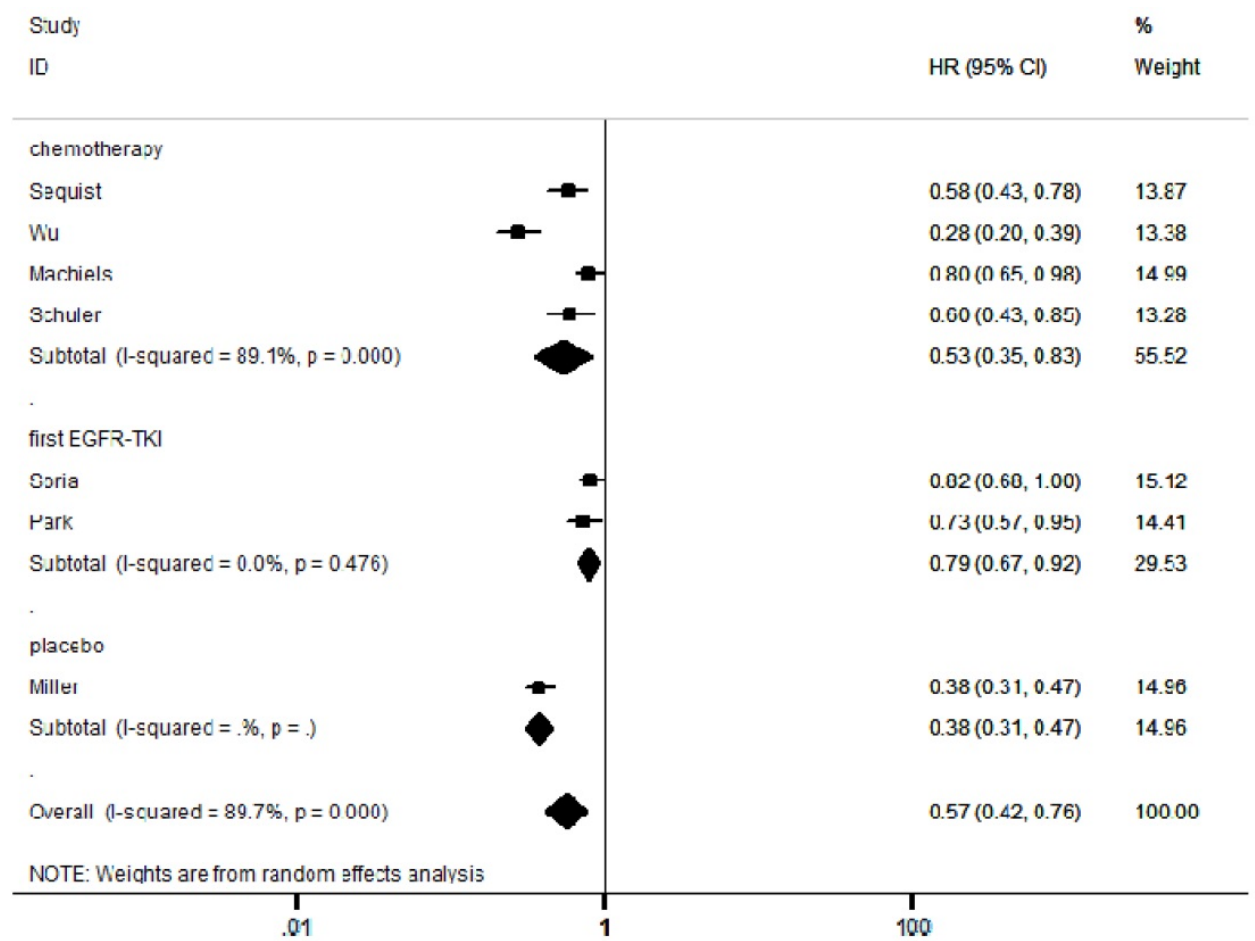

Figure 3. Forest plots of harzard ratios (HRs) for PFS comparing afatinib-based regimens to the control arm

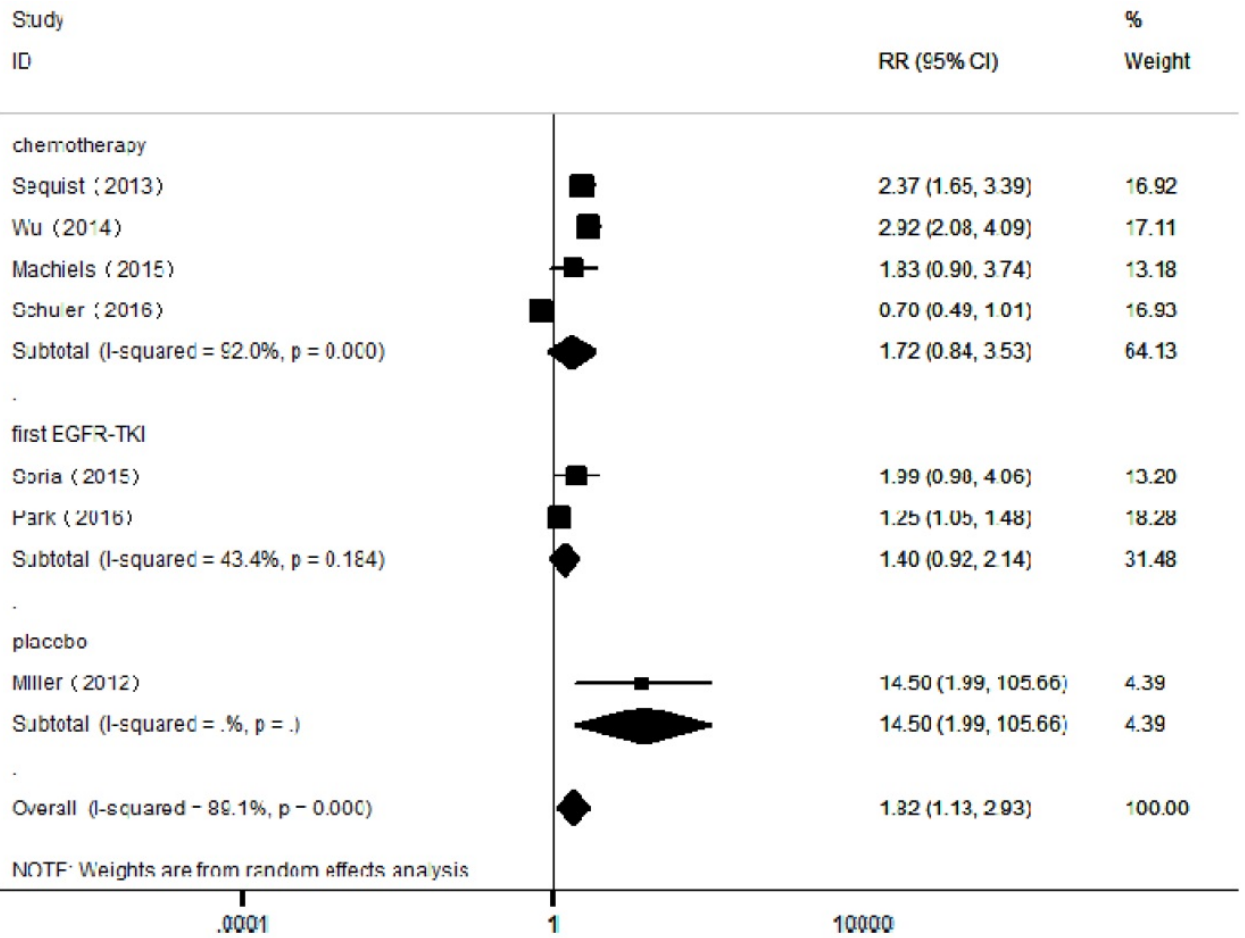

Figure 4. Forest plots of relative ratios (RR) for ORR comparing afatinib-based regimens to the control arm 


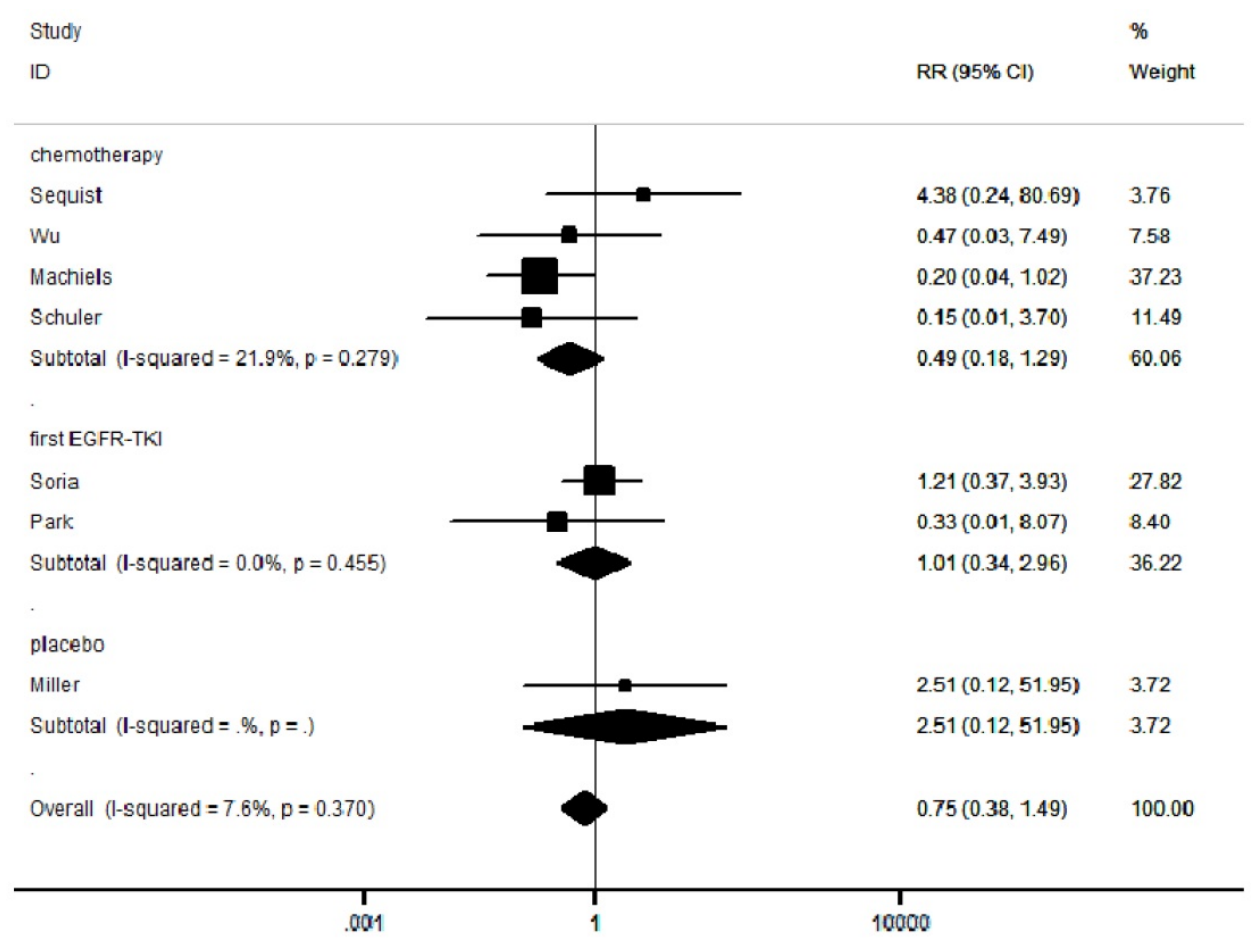

Figure 5. Forest plots of relative ratios (RR) for FAE comparing afatinib-based regimens to the control arm

\section{Discussion}

Acquired resistance to first-generation EGFR-TKIs has emerged as a critical issue in the management of NSCLC patients with EGFR mutations. Therefore, the search for new EGFR-TKIs is becoming necessary. Afatinib, a second-generation EGFR-TKI, has been approved by the FDA to treat advanced NSCLC patients harboring EGFR mutations. However, its efficacy is still controversial and no significant improvement in survival benefit has been demonstrated in several published RCTs. The purpose of this meta-analysis is to systematically assess the efficacy and safety of afatinib in the treatment of advanced NSCLC, regardless of EGFR mutational status. To the best of our knowledge, this is the first study to evaluate the efficacy and the treatment-related mortality of afatinib in treating patients with advanced NSCLC. This meta-analysis used appropriate statistical methods to compare the PFS, OS, ORR and safety of afatinib with placebo, first-generation EGFR-TKIs (i.e. erlotinib and gefitinib) and chemotherapy, based on all available information from phase II and III RCTs.

The primary outcome of this meta-analysis was PFS, it's not affected by the mixed effects of cross-treatment or follow-up treatment, and it can better reflect the effect of current treatment on tumor growth. The secondary outcomes were OS, ORR and safety. The effects of afatinib on PFS and OS were measured by $\mathrm{HR}$ with $95 \% \mathrm{CI}$, whereas ORR and safety were estimated by RR with $95 \%$ CI. For PFS and
OS measurements, $\mathrm{HR}<1$ indicates that the efficacy of afatinib group is greater to that of control groups while HR $>1$ shows the opposite. Notably, afatinib treatment significantly improved PFS (HR $=0.57,95 \%$ CI: 0.42-0.76; P $=0.0001)$ and $\mathrm{OS}(\mathrm{HR}=0.91,95 \% \mathrm{CI}$ : 0.83-0.99; $\mathrm{P}=0.04$ ) in NSCLC patients, as compared to control groups (i.e. placebo, first-generation EGFR-TKIs and chemotherapy agents). In the subgroup analysis stratified by control types, a higher OS rate was observed in NSCLC patients treated with afatinib compared to first-generation EGFR-TKIs, with a HR of 0.82 (95\% CI: 0.72-0.95). In addition, afatinib was associated with a better PFS than first-generation EGFR-TKIs, with a HR of 0.79 (95\% CI: 0.67-0.92). These results are consistent with the initial aim of the developers of afatinib, which is to improve clinical outcomes of NSCLC patients [11, 25]. Afatinib inhibits the kinase activity of all four members of the ErbB family, which can block EGFR-HER2-mediated tumor cell signaling and suppress tumor cell proliferation and metastasis. This irreversible inhibition is more effective and long-lasting compared with the reversible effect of first-generation EGFR-TKIs [14, 26]. However, there were no significant differences between afatinib vs. chemotherapy $(\mathrm{HR}=0.94, \mathrm{P}=0.36)$ and afatinib vs. placebo $(\mathrm{HR}=1.08, \mathrm{P}=0.51)$. For ORR measurement, $\mathrm{RR}<1$ demonstrates that the efficacy of afatinib group is inferior to that of control groups, while RR $>1$ represents the opposite. To our surprise, we found that the ORR of NSCLC patients was significantly 
higher in afatinib group (RR 1.82, 95\% CI: 1.13-2.93; P $=0.01)$ compared to control groups, indicating the efficacy of afatinib is greater than that of other treatment groups.

Recently, Yang et al. have performed a meta-analysis involving two observational studies to compare the efficacy between afatinib and first-generation EGFR-TKIs. One study has compared the three agents with regard to their effects on PFS and another one has investigated on adverse events only [27]. In addition, the meta-analysis has included two RCTs that compared afatinib with gefitinib and erlotinib in terms of efficacy and safety outcomes [27]. The meta-analysis concluded that afatinib improved PFS and OS compared to erlotinib, but did not improve OS compared to gefitinib. A possible explanation for these findings is that PFS is a primary endpoint in several studies, whereas OS is the opposite, which results in a lack of sufficient capacity to detect the differences in OS. Furthermore, OS may be affected by several factors such as different control groups, afatinib doses, different histological grades of NSCLC and different follow-up periods. Therefore, further studies are warranted to examine the association between afatinib and OS of NSCLC patients, and the mechanisms involved. Taken together, as a new targeted anticancer agent, afatinib appears to be an effective treatment for patients with advanced NSCLC.

The effectiveness and safety of a drug are of equal importance. In order to assess the safety of afatinib, we extracted FAE data from all the included studies. FAE is defined as a death caused by the use of pharmaceutical agent [28]. Overall, the incidence of FAE is very low, but it is an important iatrogenic cause for hospitalization and death in the United States [29]. For safety measurement, RR $<1$ indicates that afatinib is safer than control groups, while RR $>1$ signifies the opposite. Interestingly, this meta-analysis revealed that FAE was lower (RR 0.75, 95\% CI: 0.38-1.49) in afatinib group compared to control groups, but the differences were not statistically significant. Furthermore, our meta-analysis showed a significant increase in afatinib-related grade $\geq 3$ treatment-related adverse events (diarrhea, rash and stomatitis events) in the afatinib group compared to the control groups. In particular, the RR of diarrhea, rash and stomatitis in NSCLC patients treated with afatinib were $8.90,7.31$ and 6.45 , respectively. These adverse reactions can be minimized through nursing treatment, preventative information and rapid adverse event management, without leading to treatment discontinuation [30].

To sum up, this study meta-analyzed the efficacy and safety of afatinib, which provides more conclusive evidence on the use of this drug in NSCLC treatment. Additionally, we systematically assessed the complete and comprehensive datasets, which allowed us to obtain accurate estimation and perform subgroup analysis according to different treatment regimens. More importantly, there was no evidence for publication bias in this meta-analysis. Furthermore, between-study statistical heterogeneity (I2 $=0 \%$ ) was not significantly observed in the meta-analyses of OS and FAE, while random-effects models were applied on the analyses of PFS and ORR. As a result, the present meta-analysis has a higher power in illustrating the clinical implication of afatinib compared to previous RCTs and meta-analysis, which can help clinicians to make appropriate evidence-based treatment decisions for NSCLC patients who resistant to first-generation EGFR-TKIs.

Nevertheless, there were several limitations in this meta-analysis. First, this study performed a comprehensive database search, but the overall sample size was relatively small, and thus the statistical performance of certain outcome indicators may be limited. Second, this meta-analysis was based on published literature only, and thereby lacking of individual patient data. Third, subgroup analysis was not conducted on first-generation EGFR-TKIs, which required at least three studies for the comparison of afatinib with erlotinib and gefitinib. In addition, meta-regression analysis was not carried out since less than ten studies were included in this meta-analysis, and thus the results may possess a low power for the assessment of bias and confounding factors. Finally, insufficient data were available from the included studies, and some of them failed to perform subgroup analysis and control the potential confounding factors, such as afatinib doses.

\section{Conclusions}

Our current analysis suggests that the application of afatinib in the treatment of advanced NSCLC results in a significant therapeutic effect and tolerable toxicity, regardless of EGFR mutations. Further studies are needed to compare the efficacy and safety of afatinib at different doses, in different tissue subtypes and in treatment-resistant NSCLC.

\section{Supplementary Material}

Supplementary figures.

http://www.jcancer.org/v10p0885s1.pdf

\section{Acknowledgments}

This work is supported by National Natural Science Foundation of China (Grant No. 81572255) 


\section{Competing Interests}

The authors have declared that no competing interest exists.

\section{References}

1. Siegel RL, Miller KD, Jemal A. Cancer Statistics, 2017. CA Cancer J Clin. 2017; 67:7-30

2. Wakelee H, Kelly K, Edelman MJ. 50 Years of progress in the systemic therapy of non-small cell lung cancer. Am Soc Clin Oncol Educ Book. 2014; 177-189.

3. Filipits M, Pirker R. Predictive markers in the adjuvant therapy of non-small cell lung cancer. Lung Cancer. 2011; 74:355-363.

4. Zhao M, Li H, Li L, Zhang Y. Effects of a gemcitabine plus platinum regimen combined with a dendritic cell-cytokine induced killer immunotherapy on recurrence and survival rate of non-small cell lung cancer patients. Experimental and Therapeutic Medicine. 2014; 7:1403-1407.

5. Barnes CJ, Kumar R. Epidermal growth factor receptor family tyrosine kinases as signal integrators and therapeutic targets. Cancer Metastasis Rev. 2003; 22:301-307.

6. Morin-Ben Abdallah S, Hirsh V. Epidermal Growth Factor Receptor Tyrosine Kinase Inhibitors in Treatment of Metastatic Non-Small Cell Lung Cancer, with a Focus on Afatinib. Front Oncol. 2017; 7:97-97.

7. Gahr S, Stoehr R, Geissinger E, Ficker JH, Brueckl WM, Gschwendtner A, et al. EGFR mutational status in a large series of Caucasian European NSCLC patients: data from daily practice. Br J Cancer. 2013; 109:1821-1828.

8. Tan DSW, Yom SS, Tsao MS, Pass HI, Kelly K, Peled N, et al. The International Association for the Study of Lung Cancer Consensus Statement on Optimizing Management of EGFR Mutation-Positive Non-Small Cell Lung Cancer: Status in 2016. J Thorac Oncol. 2016; 11:946-963.

9. Mitsudomi T, Morita S, Yatabe $Y$, Negoro S, Okamoto I, Tsurutani J, et al. Gefitinib versus cisplatin plus docetaxel in patients with non-small-cell lung cancer harbouring mutations of the epidermal growth factor receptor (WJTOG3405): an open label, randomised phase 3 trial. Lancet Oncol. 2010; 11:121-128.

10. Giordano P, Manzo A, Montanino A, Costanzo R, Sandomenico C, Piccirillo $\mathrm{MC}$, et al. Afatinib: An overview of its clinical development in non-small-cell lung cancer and other tumors. Crit Rev Oncol Hematol. 2016; 97:143-151.

11. Hirsh V. Next-Generation Covalent Irreversible Kinase Inhibitors in NSCLC: Focus on Afatinib. Biodrugs. 2015; 29:167-183.

12. Hirsh V. New developments in the treatment of advanced squamous cell lung cancer: focus on afatinib. Onco Targets Ther. 2017; 10:2513-2526.

13. Yang JCH, Sequist LV, Zhou C, Schuler M, Geater SL, Mok T, et al. Effect of dose adjustment on the safety and efficacy of afatinib for EGFR mutation-positive lung adenocarcinoma: post hoc analyses of the randomized LUX-Lung 3 and 6 trials. Ann Oncol. 2016; 27:2103-2110.

14. Solca F, Dahl G, Zoephel A, Bader G, Sanderson M, Klein C, et al. Target Binding Properties and Cellular Activity of Afatinib (BIBW 2992), an Irreversible ErbB Family Blocker. J Pharmacol Exp Ther. 2012; 343:342-350.

15. Bennouna J, Vera SRM. Afatinib-based combination regimens for the treatment of solid tumors: rationale, emerging strategies and recent progress. Future Oncol. 2016; 12:355-372.

16. Higgins JPT, Thompson SG, Deeks JJ, Altman DG. Measuring inconsistency in meta-analyses. BMJ. 2003; 327:557-560.

17. Higgins, JPT, Altman DG, Gotzsche PC, Juni P, Moher D, Oxman AD, et al. The Cochrane Collaboration's tool for assessing risk of bias in randomised trials. BMJ. 2011; 343: d5928.

18. Miller VA, Hirsh V, Cadranel J, Chen YM, Park K, Kim SW, et al. Afatinib versus placebo for patients with advanced, metastatic non-small-cell lung cancer after failure of erlotinib, gefitinib, or both, and one or two lines of chemotherapy (LUX-Lung 1): a phase $2 b / 3$ randomised trial. Lancet Oncol. 2012; 13:528-538.

19. Sequist LV, Yang JCH, Yamamoto N, Hirsh V, Mok T, Geater SL, et al. Phase III Study of Afatinib or Cisplatin Plus Pemetrexed in Patients With Metastatic Lung Adenocarcinoma With EGFR Mutations. J Clin Oncol. 2013; 31:3327-3334.

20. Wu YL, Zhou C, Hu CH, Feng JF, Lu S, Huang YC, et al. Afatinib versus cisplatin plus gemcitabine for first-line treatment of Asian patients with advanced non-small-cell lung cancer harbouring EGFR mutations (LUX-Lung 6): an open-label, randomised phase 3 trial. Lancet Oncol. 2014; 15:213-222.

21. Machiels JPH, Haddad RI, Fayette J, Licitra LF, Tahara M, Vermorken JB, et al. Afatinib versus methotrexate as second-line treatment in patients with recurrent or metastatic squamous-cell carcinoma of the head and neck progressing on or after platinum-based therapy (LUX-Head \& Neck 1): an open-label, randomised phase 3 trial. Lancet Oncol. 2015; 16:583-594.

22. Soria JC, Felip E, Cobo M, Lu S, Syrigos K, Lee KH, et al. Afatinib versus erlotinib as second-line treatment of patients with advanced squamous cell carcinoma of the lung (LUX-Lung 8): an open-label randomised controlled phase 3 trial. Lancet Oncol. 2015; 16:897-907.

23. Park K, Tan EH, O'Byrne K, Zhang L, Boyer M, Mok T, et al. Afatinib versus gefitinib as first-line treatment of patients with EGFR mutation-positive non-small-cell lung cancer (LUX-Lung 7): a phase 2B, open-label, randomised controlled trial. Lancet Oncol. 2016; 17:577-589.
24. Schuler M, Yang JCH, Park K, Kim JH, Bennouna J, Chen YM, et al. Afatinib beyond progression in patients with non-small-cell lung cancer following chemotherapy, erlotinib/gefitinib and afatinib: phase III randomized LUX-Lung 5 trial. Ann Oncol. 2016; 27:417-423.

25. Chen XF, Zhu Q, Zhu LJ, Pei D, Liu YQ, Yin YM, et al. Clinical perspective of afatinib in non-small cell lung cancer. Lung Cancer. 2013; 81:155-161.

26. Riely GJ, Politi KA, Miller VA, Pao W. Update on epidermal growth factor receptor mutations in non-small cell lung cancer. Clin Cancer Res. 2006; 12:7232-7241.

27. Yang ZY, Hackshaw A, Feng Q, Fu XH, Zhang YL, Mao C, et al. Comparison of gefitinib, erlotinib and afatinib in non-small cell lung cancer: A meta-analysis. Int J Cancer. 2017; 140:2805-2819.

28. Heron M, Hoyert DL, Murphy SL, Xu JQ, Kochanek KD, Tejada-Vera B, et al. Deaths: final data for 2006. Natl Vital Stat Rep. 2009; 57:1-134.

29. Lazarou J, Pomeranz BH, Corey PN. Incidence of adverse drug reactions in hospitalized patients: a meta-analysis of prospective studies. JAMA. 1998; 279:1200-1205.

30. Marquez-Medina D, Popat S. Afatinib: a second-generation EGF receptor and ErbB tyrosine kinase inhibitor for the treatment of advanced non-small-cell lung cancer. Future Oncol. 2015; 11:2525-2540. 